\title{
Lapurdum
}

Euskal ikerketen aldizkaria | Revue d'études basques |

Revista de estudios vascos | Basque studies review

$7 \mid 2002$

Numéro VII

Maurice Harrieten (1841-1904) euskara-frantsesa hiztegi-eskuizkribua : ikerketa lexikografikoa. A, K eta $\mathrm{T}$ hizkiak, (tesiaren laburpena).

\section{Arantxa Hirigoyen}

\section{OpenEdition}

\section{Journals}

Édition électronique

URL : http://journals.openedition.org/lapurdum/1038

DOI : 10.4000/lapurdum.1038

ISSN : 1965-0655

Éditeur

IKER

Édition imprimée

Date de publication : 1 octobre 2002

Pagination : 339-360

ISBN : 2-86781-321-2

ISSN : $1273-3830$

\section{Référence électronique}

Arantxa Hirigoyen, « Maurice Harrieten (1841-1904) euskara-frantsesa hiztegi-eskuizkribua : ikerketa lexikografikoa. A, K eta T hizkiak, (tesiaren laburpena). », Lapurdum [Linean], 7| 2002, Sarean emana---an 01 juin 2009, kontsultatu 22 avril 2019. URL : http://journals.openedition.org/lapurdum/1038 ; DOI : 10.4000/lapurdum.1038 


\section{Positions de recherche - Ikerketa aurkezpenak}

\section{Arantxa HIRIGOYEN}

\section{Maurice Harrieten (1841-1904) euskara-frantsesa hiztegi-eskuizkribua : ikerketa lexikografikoa. A, K eta T hizkiak, (tesiaren laburpena).}

Joan den otsailaren 12an Baionako fakultatean aurkeztutako Maurice Harrieten (18141904) euskara-frantsesa hiztegi-eskuizkribua : ikerketa lexikografikoa. $A$, K eta $T$ hizkiak tesi-lanaren laburpena kausituko da segidan. Gisa bereko idazki batean dena ezin denez aipatu, ustez tesi honetako ardatz nagusiak aipatuko ditut; eta bereziki Harrieten hiztegiaren ezaugarri nagusiak.

Maurice Harriet hiztegigile haltsuarra :

Grand et svelte, d'un visage singulièrement noble et fier, ne dédaignant pas certaine élégance dans sa mise, prédicateur éloquent, très l7è siècle (DIBILDOS $1926: 601$ ).

Maurice Harriet 1814. urteko buruilaren 14an sortu zen Haltsun eta 1904. urtean, 90 urtetan bere sorterrian zendu zen. Zazpi haurridetan bosgarrena, Maurice, bere anaia Fabien bezala, apeza zen. Larresoroko seminario ttipian hasi zituen bere ikasketak. Ondotik, Pasaiako (Gipuzkoa) jesuita frantsesen ikastetxerat joan zen. Badakigu, Pasaiatik landa Larresoroko seminario ttipira itzuli zela irakasle lanetan aritzeko. 1835. urtean Meaux ondoan eta Parisetik hurbil den Juilly hirian segitu zuen lanean irakasle gisa. Handik lau urtetara, 1839. urtean, Maurice Harriet 25 urterekin Saint-Sulpice-ko seminarioan sartu zen apezgai. Apez izendatu zuten 28 urte zituelarik (1842. urtean), ondotik Baionarat itzuli zen. Han, Fabien Harriet, bere anaiarekin batera sortu zuen "Institution Saint-Léon" ikastetxean lan egin zuen, giza-zientzietako irakasle gisa bai eta zuzcndari gisa ere. Baionako ikastetxe horretan bederatzi urtez egon ondoan, 1850. urtean, Baionako Seminario handiko irakasle izendatu zuten. Bost urtez (1850-55) egon zen Baionako Seminarioan.

1855. urteko primaderan, Maurice Harriet Madrilgo "San Luis de los Franceses" izeneko eliza, eskola eta eritetxearen buru izendatua izan zen. Gertakari hau, biziki garai garrantzitsua dugu Maurice Harrieten bizitzan. Madrilgo San Luis de los Franceses ikastetxean 1878a arte egon zen. Madrilen iragan zuen garai luze hartan, Jose Francisco Aizkibel (1798-1865) hiztegigile azkoitiarra ezagutu zuen eta adiskide handia izan zuen. Gaztelania biziki ongi menperatzeaz gain hego Euskal Herri osoko euskalkien hobeki ezagutzeko eta lantzeko parada izan zuen, han ezagutu zituen euskal unibertsitariei esker bereziki.

1878. urtean, berriz, Haltsura itzuli zen bere sortetxera. Maurice Harrieten eguneroko bizia hiru eginkizunetan bereizten zen : bizi publikoa Haltsun, euskal hiztegiaren inguruko lana eta ihizia.

Ez da batere errexa jakitea xuxen noiz hasi zen bere hiztegi erraldoiaren idazten. Lhanden arabera (Knorr 1987 : 25), 1878. urtean hasi zen. Iduri luke jadanik, Madrilera joan aitzin hiztegiaren xedea mamitua zuela. Euskalzaleen munduan denek bazakiten Harriet 
hiztegi baten prestatzen ari zela. Hona hemen, Duvoisin-en eskutitza Bonaparte-i igorria, 1880.urteko azaroan :

L'abbé Maurice Harriet occupe ses loisirs à bâtir un Dictionnaire basque. Reconnaissant qu'une telle oeuvre est de trop longue haleine pour l'homme qui s'y prend tard, il cherche des collaborateurs. Mieux lui vaudrait de faire un Vocabulaire, dans le genre de celui de Salaberry, quoique avec plus d'étendue [...]. (Daranatz $1931: 57$ ).

1883. urtean berriz, hona zer dion Duvoisin berak, Abbadie-ri :

Il y a un an, il vint (M. Harriet) me trouver, un peu découragé par l'immensité du travail; il me proposa de fondre son effort avec le mien. C'était pour moi un mauvais moment. J'avais plus d'une affaire désagréable sur les bras, et de dégoût je me disposais à quitter Bayonne. Si cet été je me détermine à aller passer quelques jours à Halsou, je verrai ce que l'abbé a fait (Daranatz 1931:70).

Bere azken urteetan, osagarriarengatik Maurice Harriet ez zen gehiago publikoki agertzen. 1904. urteko otsailaren 16an, buruilan 90 urte beteko zituelarik, zendu zen Harriet hiztegigilea, bere hiztegia argitara eman gabe.

\section{Hiztegiaren aurkezpen orokorra : ezaugarri nagusiak}

Harrieten hiztegiaren ezaugarri nagusiena eskuizkribua dela da, hau da sekulan argitaratua izan ez den obra bat da. Orotara 3536 hosto ditu, alfabetikoki sailkatuak Atik Zraino. Hizki guziak zenbakituak dira eta karpeta desberdinetan sailkatuak.

Bestalde, erraten ahal da hiztegi elebiduna dela, hau da euskara-frantsesa hiztegia. Sarrerahitzak euskaraz agertzen dira eta mugabideak frantsesez; hots, frantsesez esplikatzen ditu euskal hitzak. Elebiduna ez bakarrik mugabideetan, Harrietek erabiltzen dituen etsenplu eta aipu oro frantsesera itzultzen baititu.

Hemen aipatu beharreko beste ezaugarri nagusi bat, nahiz gero makroegituran aipatuko dugun berriz, euskalki guziak konduan hartzen dituela da. Harrieten hiztegian ez dira bakarrik lapurtera, behenafarrera edo zubererazko hitzak agertzen, baizik eta euskalki guziak. Gisa horretan euskal lexikoaren erakusgai zabala eskaintzen digu. Gipuzkera, bizkaiera, goi-nafarrera bereiziz, baita zenbait aldiz Ipar nahiz Hego Euskal Herriko berezitasunak bereiziz ere (dialectes cispyrénéen eta dialectes transpyrénéens). Hona hemen zenbait adibide erakusgai gisa :

Achiruina : l. id. achiroina, achoina Sy. zango cabila l., zango-aztala-aztal-beharria : BN, S. cheville du pied : id. g.b. isuriña-churminoa, orgatilla, oindagora, izuriña. [...]

Aguia : [...] 3. Aguian [...] Sy. lg. behar bada, menturaz, BN, S. heldu, heltu bada, b. ausaz, ausa, aiyaz, apercon bai, b. beharbada bai l.g.BN.S. - nasqui, nabasqui g. noasqui g.b. [...].

Ainhara : L, ainhera BN, S., inhara L, enada, elaia, ainada g.b. [...] 
Ardoa g. ardaua b., arnoa l.BN, anoa, anhoa, S.BN - le primitif est ardo, comme l'emploient le g. et b., et ainsi que l'indiquent ses composés dans les autres dialectes: ardanasca, ardantza, etc-

Euskalkien aipamena hiztegiaren aberastasunetariko bat da dudarik gabe; eta xehetasun interesgarriak eskaintzen ditu hiztegigileak alde horretatik. Horrek frogatzen digu Harrietek bere ezagutza eta jakitateaz aparte iturri anitz eta desberdinak erabili zituela bere hiztegiaren osatzeko.

\section{Makroegitura edo egitura nagusia}

Preseski euskal lexikoaren erakusgai zabal horrek, hiztegiaren makroegitura finkatzen eta osatzen du. Tesi-lanerako hautatu ditudan hiru hizkiek $(A, K, T)$ erakusgai zabala eskaintzen dute, sarrera-hitzen kopurua oparoa izanik. $A$ hizkian 1512 hitz edo sarrera kausitzen ahal da, $K$ hizkian 490 eta $T$ hizkian 855 . Hala ere, makroegitura edo izendegiaren sailkapenari dagokionez, hiru hizki horien artean ez dugu sailkatze molde bera atzeman. Hau da, Harietek ez ditu molde berean aurkezten $A$ hizkiko sarreak eta $K T$ hizkikoak. $A$ hizkian, sarrera nagusiaren pean sailkatzen ditu erro edo jatorri bereko beste sarrerak :

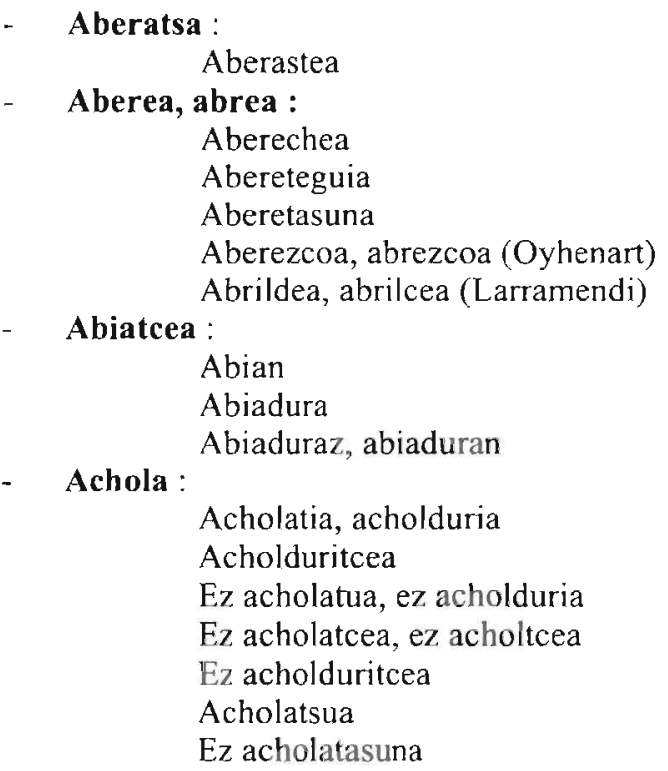

Eginmolde honetan, hiztegigileak jatorri bereko hitz edo unitate lexikal guziak juntatu ditu multzo bakar batean edo lema bakar baten pean. Gisa horretan hitzaren erroa eta bere egitura argi ageri dira. Hala ere, horrek arran nahi du irakurleak hitzaren jatorria ezagutu behar dủela lehenagotik. Bestalde, sailkapen molde honek ez du orden alfabetikoa errespetatzen. Baina iduri luke Harrietek beste jokamolde bat hautatu duela hiztegia egiten ari den heinean. $K$ eta $T$ hizkietan adibidez, hitz bakoitzari sarrera bat eskaintzen dio : 
khailua

khallatua

khailutcea

khamutsa

kailutsua

hamustea

k(h)alda

khamuscorra

khaldagarria

khamusdura

khaldaquizuna

khamustasuna

khaldatcea

kharatsa

khaldatzailea

kharasduna

khalitcha

kharasdura

khalitchaduna

kharasgarria

khalitchatcea

kharastasuna

khallatcea

kharast

Adibide zerrenda honi so eginez, aldiz, hitzak ez dira gehiago erroaren edo jatorrizko sarrera-hitzaren inguruan kokatuak, baizik eta denak sarrera-buru gisa aurkeztuak dira.

Sarrera-hitzen sailkapenak ezaugarri nagusi bat badu : izen arrunta eta adjektibo guziak forma mugatuan emanak dira. Aditzak, aldiz, partizipiotik abiatuz denak aditzizen moldean aurkeztuak dira; $K$ eta $T$ hizkietan, gainera, aditzaren hiru formak ageri dira :

\section{A hizkia :}

- Abarkatzea : "embrasser, enserrer"

- Abarrakitzea : "mettre en menus morceaux"

- Abaztorratcea : "éloigner de soi, rejeter quelqu'un avec humeur ou violence"

- Abiatcea : "se mettre en voie de..., se préparer, s'acheminer, commencer"

Afaltcea : "souper"

- Aguertcea : "1- verbe transitif, découvrir, montrer, manifester - 2- verbe intransitif, apparaître, être clair, visible

- Aguitcea : "1-arriver, contingere - 2 Devenir, fieri"

\section{K eta T hizkiak :}

Kkabarstea, khabarts, khabarstu, khabarsten : "I - v.act. Sécher à la chaleur, jusqu'à complète siccité et jusqu'au recoquillement - 2-v.intrans. Se recoquiller à la chaleur" 
- Khaldatcea, khalda, khaldatu, khaldatcen : " 1 - v.act. Donner une chaude, une chauffe au feu de forge - 2-Souder un métal à lui même ou à un autre métal, après les avoir amollis au feu"

- Khamustea, khamuts, khamustu, khamusten : "I- v.act. Emouseer le tranchant, le fil, la pointe - 2-v.intransiti. S'émousser - 3- au fig. émousser, ou s'émousser, en parlant des sentiments, de facultés"

- Talastatcea, talasta, talastau (sic), talastacen : "agiter un liquide, le remuer avec plus ou moins du bruit, en uvase non plein entièrement // s'agiter, se remuer, en parlant d'un liquide en un vase"

- Talcatcea, talca, talcatu, talcatcen : "frapper de la tête en parlant de bêtes à cornes, taureaux, et principalement béliers"

Tapatcea, tapa, tapatu, tapatcen : "1- fermer, boucher ce qui est ouvert - 2Couvrir ce qui est découvert - 3- au fig. fermer la bouche"

Azkenik, hiztegiaren izendegian beste sarrera motak agertzen dira : interjekzioak eta onomatopeiak. Laburki aipatu dugunaren arabera Maurice Harrietek izendegi zabala eta aberatsa eskaintzen du bere hiztegian. Alde batetik, euskalki guziak kondutan hartuu ditu izendegia osatzeko eta bestetik, makroegituraren arabera bederen, erraiten ahal da hizkuntza hiztegi baten ezaugarriak dituela.

\section{Mikroegitura edo egitura xehea}

Makroegitura finkatu ondoan, hiztegigileak hiztegi-artikuluak osatu behar ditu hots mikroegitura antolatu bechar du. Harrieten hiztegian, lehen behakoan argi da hiztegi artikuluek ez dutela denek egitura bera. Halaber, hona hemen sarrera-hitz nagusiaren ondotik maiz agertzen diren osagaiak :

- Sarrera-hitza

- Aldakia

- Mugabidea edo definizioa

- Adibidea edo aipua

- Sinonimoa

- Etimologia edo hitz-iturburua

- Oharrak

Ezaugarri bakoitza banaka ikertzea luze izanen delakoan, aipamen berezia egin nahiko nuke adibide edo aipuei buruz. Harrieten euskara-frantsesa hiztegia idazleen aipuz josia da; eta preseski hori hiztegiaren berezitasun handi bat da. Oroitarazi behar dut hemen, hiztegiaz aparte, tesi-lanean beste bi dokumentu berriren aipamena egin dudala. Batetik, Cahier de notes' izeneko liburuxka baten berri ematen dut eta bestetik, haltsuar hiztegigileak bere etxeko liburutegian zituen obra guzien zerrendaren berri. Berrehunetik gora obra zenbatu ditugu eta dudarik ez da Harrietek, liburu zerrenda horretatik edan duela. Lau mende baino gehiago estaltzen duten liburu eta obrak dira, baita eskuizkribuak ere, literatura, erlijio, historia nahiz beste gairi buruzkoak. XIX. mende hondarrean hasi ziren hiztegigileak aipuen sartzen eta bereziki aitzinako literaturan sustraituak ziren etsenpluak. Eginmolde honek frogatzen du hain segur ere, hiztegigilea biltzaile izan zela eta ez asmatzaile. Harrietek ez baitu hitz bakar bat ere asmatu; izendegian aurkeztu dituen sarrera kasik guziak idazle baten

Hiztegia, Cahier de notes eta Harrieten liburutegiko obren zerrenda Baionako apezpikutegian atxikiak dira gaur egun. 
adibide batekin uztartuak dira. Tesi-lanean $A, K$ eta $T$ hizkietan agertzen diren idazle edo obra guzien laburdurak argitu ondoan, zerrendatu ditugu eta bide batez maiztasuna neurtu ere. Hiztegi batendako aipuak edo adibideak beharrezko osagaiak dira. Gure kasuan, Euskara-frantsesa hiztegiak informazio iturri aberatsa eskaintzen digu ikuspegi horretatik.

\section{Zer hiztegi mota ote da?}

Hiztegiaren makroegitura eta mikroegituraren arabera eta hemen laburbilduz aipatu ditugun ezaugarrien arabera, Harrieten hiztegiko 3536 orriek izaera desberdinak bereganatzen dituzte.

Hiztegi orokorra edo orotarikoa dela, dudarik ez da. Orokorra da, ez baitu preseski gai edo alor berezi bateko hiztogia oinarritzat hartzen, hizkuntza bere osotasunean baizik. Makroegitura zabala eta anitza eskaintzen dute Harrieten hiztegiko 3.536 hostoek. Harrietek bere garaiko joera islatzen du, izendegiari eta hiztegi antolakuntzari begira bederen.

Hizkuntza bere osotasunean kondutan hartzen duela erran dugu, hortaz hizkuntza hiztegia badela ezin uka. Hizkuntzari buruzko hiztegia izanik, euskara eta euskalki guziak aipatzen ditu; ezaugarri horrek hiztegiari aberastasun handi bat ematen dio, eta irakurlearentzat euskarari buruzko informazio iturri nagusia bilakatzen da hiztegia.

Mikroegituran aztertu ditugun mugabideetan oinarrituz, hiztegi entziklopediko baten itxura ere hartzen diogu batzuetan. Definizio gramatikalaz gain, definizio entziklopedikoak kausitu ditugu. Baina izaera entziklopediko hori ez da bakarrik definizioetan nagusitzen, makroegituran ere agertzen da. Hainbat gai bereziren inguruan kausitzen ahal dira sarrerak : lan-tresna, txori, landare eta lore izenez apaindua da hiztegia. Euskalki guzietarat hedatzen den hiztegi honek, badu beste osagailu adierazgarri bat : euskal literaturari buruzko lekukotasunak. Lekukotasunak, hiztegian barna aho nahiz luma hizkuntzakoak dira. Eta ez badira beti ere behar den bezala aurkeztuak (erreferentzi eskasak), Harrietek aipuen bidez euskal literaturaren erakusgai luze-zabala eskaintzen du. Edizio berriak nahiz zaharrak, eskuizkribuak ere ez ditu bazter utzi. Hortaz, ikuspegi hortatik bederen hiztegi historikoa dela erraten ahal da. Mendez mende aipatzen dituen idazle eta obren bitartez, hizkuntzaren bilakaeraren berri ematen digu. Zer erranik ez hiztegi elebiduna dela, euskara-frantsesa. Frantsesez esplikatzen ditu euskal hitzak. Ezaugarri honek, hiztegiaren erabiltzailea edo irakurle mota finkatzen du. Harrieten hiztegiak publiko desberdinak erakartzen ahal ditu : euskara ez dakiena, euskara ikasten ari dena edo euskalduna dena. Hautu horrek, itzultzaile lanetan aritzea eragin dio. Adibide eta aipu guziak frantsesera itzuli baititu, hortaz lan bikoitza bete du Harrietek : lexikografo lana eta itzultzaile lana.

Azkenik haltsuarraren hiztegia, hiztegi arauemailea izendatzea egokia iduritzen zaigu. Hiztegi-artikuluetan usu irakurri dugun bezala, irakurleari sarrera-hitzari buruzko gomendioak edo aholkuak luzatzen dizkio. Forma hau hobesten duela bestea baino, hitza ez dela gehiago erabiltzen (inusite), asmatua dela (inventé) eta bestelako oharrak agertzen dira hainbat aldiz. Hiztegiaren xede nagusia informatzea izanik, Harrietek beste funtzio bat betetzen du, hizkuntzaren erabilpen ona bermatuz. 


\section{Harriet XIX. mendean :}

Maurice Harrieten lana XIX. mende erditsutik hasi eta hondarrera bitartean kokatzen dugu. Oroitaraz dezagun XIX. mende erditsutan, 1853. urtean Larramendiren hiztegi hirukoitzaren bigarren argitalpena jalgi zela. Argitalpen berriak, aldiz, emeki-emeki agertzen hasi ziren. Euskararen irakasliburuak eta gramatika deskribatzailea oinarri zuten lan laburrak izan ohi ziren : orrixkak, eranskinak eta esku-liburuñoak. Euskal Herrian edo atzerrian argitaratuak, euskararen deskribapen, arau, paradigma, hiztegiño eta adibideak eskaintzen zituzten : Moguel 1801, Lécluse 1826, Astigarraga 1825, Fabre 1870, van Eys 1873, Aizkibel, Novia del Salcedo eta Duvoisin-en lanek besteak beste ez zuten beren garaian argitaratzeko paradarik ezagutu, edo berantago atera ziren plazarat. Eta bistan dena, zerrenda horretan kokatzen dugu Harrieten hosto dituen hiztegia.

Bestalde, ez bada xuxen jakiterik noiz hasi zen hiztegiaren idazten, oro har erraten ahal dugu Harriet eta Azkue noizbait bederen, denbora berean ibili zirela bakoitza bere obraren apailatzen. Azkuek 1905-1906 urte bitartean plazaratu baitzuen hiztegia. Halere, Harriet lehenagotik hasi zen lan horretan eta kasik 30 urte luzez ihardun zuen xede horretan. 30 urte anitz da; bereziki gisa bereko obra baten gauzatzeko. Urteen joan-jinean, ohiturak, bizimoldea, pentsamoldea eta hizkuntza bera aldatzen eta berritzen dira beti eta beti.

Hiztegi aberatsa, bada, eta, erabat harturik, informazio fidagarria eskaintzen duena. Garbizalea izanik ere, Harrietek hitz guztiak jasotzen ditu, ezein ere kanpoan utzi gabe. Azkueren hiztegiaren aldean, iduritzen zaigu Harrietenak menturaz hobeki isladatzen duela 19. mendeko euskal gizartea bere osotasunean eta bizitza-sail guztietan. (Knörr 1986 : 416)

Hutsegite eta akatsak alde baterat utziz, Harrietek, euskara bere osotasunean kondutan harturik eta hiztegi elebidun batean oinarriturik, gaur egun oraino argitaratua ez den altxor bat utzi digu.

$[\ldots]$ ce dictionnaire reste une mine des plus précieuses pour les chercheurs et une oeuvre de haute valeur, le plus important des dictionnaires basques assurément après celui d'Azkué. (Lhande 1926:18)

Baina zer bilakatu ote dira gaur egun hiztegiko 3536 hostoak? Hainbeste merezimendu izan ondoan, gaur egun oraino argitara eman gabe kausitzen da. Badakigu Harrietek berak argitaratzeko eskaintzak izan zituela : D'Abbadie adiskide handiak ihardespen ezezkorra ukan zuen eskuizkribuko lehen lau letren argitaratzeko eskaintza egin ziolarik, Daranatzek ere erantzun bera ukan zuen (Knörr 1987 : 26). 1923. urteko artikulu batean (Harriet zendua zen orduko), Daranatzek Azkue eta. Euskaltzaindiari dei bat luzatu zien :

[...], je voudrais appeler l'attention de l'abbé ResurrecciónMaría de Azkue et des membres si éclairés de l'Académie Basque, dont il est le Président autorisé, sur le Dictionnaire basque-français de l'abbé Maurice Harriet. [...] je voudrais 
prier l'Académie Basque de bien vouloir envisager la possibilité de publication du Dictionnaire basque-français de l'abbé Maurice Harriet. (Daranatz 1923 : 461)

[...] elle demeure une mine extrêmement riche de remarques, d'études, de précisions. Elle ne saurait être un manuel pratique, mais les chercheurs et les savants y trouveront une foule de suggestions des plus précieuses. Nous souhaitons vivement qu'il se trouve un Mécène pour fournir la forte somme qu'exigerait à l'heure actuelle l'impression de ce magistral et monumental travail. (Lhande 1926: 18)

Baina dei eta galde horiek guziak ihardespenik dira gaur egun oraino. Egia da den bezala ez dela plazaratzen ahal haltsuarraren lana ; eta hortaz ohartua zen hain segur egilea bera. Guhaur ohartu garen bezala, hiztegian barna bilakaera bat bada. Ageri da hiztegigileak, hiztegia egiten ari zen heinean lan egiteko moldea aldatu duela, aski da ikustea jadanik aipatu ditugun $A$ eta $K / T$ hizkien arteko desberdintasunak. Hori gertatzen da 30 urtez egiten den lan batekin.

Argitaratua ez izateaz gain, beste arrengura batetaz solas egin behar dugu, ildo beretik doana hain segur. Euskal lexikografian eta oro har euskalaritzan Maurice Harrieten izena ez da ezagutua. Hiztegigintzaz mintzo delarik, bekan entzuten dugu Harrieten izena. Zergatik ote ? Alta jakina da, iturri gisa erabilia izan dela, Lhandek bereziki ; Harrieten lanari esker osatu baitu bere hiztegia. Bestalde kondutan hartu behar da, XX. mende hastapenean Azkueren hiztegiak bereganatu zituela bazter guziak, bereziki hiztegigintza munduan. Haltsuar hiztegigileak bazakien lekeitiarra hiztegi baten prestatzen ari zela. Daranatzen erranetan (Daranatz 1923), Harrietek ez zuen bere lana argitaratzerik nahi, ez bera bizi zeno ez eta bere heriotzaren ondotik ere. Egilearen nahia hori izanik ere, 3536 orriko gaitzeko lan honek argia ikustea merezi du. Isilpean airatu diren hostoak, higatzen eta xahartzen ari dira Baionako apezpikutegian gaur egun. Oroitaraz dezagun ere, gure ikerketa lan honetan dokumentu eta idazki berriak kausitu ditugula, orain arte ezezagunak zirenak. Cahier de Notes izenburupean atzeman dugun Harrieten oharren liburuxka eta bere liburutegiko obra guzien zerrenda.

2004. urtean, Maurice Harrieten (1814-1904) heriotzaren mendeurrena ospatuko da. Denbora gehiago galdu gabe eta behar diren baldintza eta baliabideak ardietsiz itzaletik atera behar dugu euskara-frantsesa hiztegia, argia ikus dezan. Egia da, hala ere irakurketa eta berridazketa lanetan zailtasunak eta trabak kausitu ditudala, hainbat urteetako orriek ikerketa lana zaildu baitute zenbait aldiz. Funtsean 30 urtez buruturiko lan bat ez da hain aise berreskuratzen. Baina hala ere, hiztegiak egin dira eta eginen dira oraino, baina zer hizkuntzek utziko luke XIX. mendeko 3536 orri dituen hiztegi elebidun bat itzalean? Hizkuntza baten iraganak geroari buruz bultzatzen gaitu dudarik gabe. Hiztegi honek gure ezagutza eta jakinduria noraino mugatua eta zuzena den islatzen digu. Euskararendako altxor eta ondare ikaragarria izateaz gain, euskal hiztegigintzaren historian badu bere lekua, ongi merezia gainera. 
Den bezala noizpeit agian argitarat ikhusiko du... bizi denak ${ }^{2}$

Hala izan bedi.

\section{Bibliografia}

1. Dibildos, 1926, "L'Abbe Maurice Harriet et sa Soeur Mademoiselle Agathe », Gure Herria, 598-680.

2. Daranatz, 1923, "Le dictionnaire Basque Espagnol Français de l'abbé R.M. de Azkue "), RIEV XIV, 457-462.

3. __ 1931, "Correspondance du Capitaine Duvoisin », RIEV, 57.

4. Knörr E., 1986, " Maurice Harriet-en hiztegiaz », ASJU, 413-417.

5. _., 1987, Para una edición critica del diccionario de Maurice Harriet. EHU (Euskal Herriko unibertsitatea) / Université du Pays-Basque, Vitoria/Gasteiz (tesi argitaragabea).

6. Lhande, 1926, Dictionnaire Basque-Français, Gabriel Beauchesne ; Paris.

\section{Marie-Hélène VELASCO-GRACIET}

\section{La frontière, le territoire et le lieu. Norme et transgression dans les Pyrénées Occidentales ${ }^{3}$.}

Depuis qu'elles existent, les frontières nationales ont intéressé les géographes. D'ailleurs, la géographie est la seule discipline scientifique à avoir consacré un de ses axes de recherches à la seule étude des frontières: la géographie des frontières. Cette géographie s'est donc construite et a connu une histoire particulière. Au fil des années de cette construction, les géographes ont constitué un corpus théorique et méthodologique. La géographie des frontières connaît aujourd'hui un regain d'intérêt de la part des géographes qui se penchent à nouveau sur "l'appareillage" à mettre en place pour mieux comprendre les frontières. S'intéresser aux frontières nationales n'exclut cependant pas la possibilité d'appréhender la frontière de façon générale, qu'elle soit nationale ou non, spatiale ou non. Plus encore, traiter de frontière sous n'importe quelle forme que ce soit peut constituer une base pertinente pour une meilleure compréhension des frontières spatiales et des frontières nationales. Avant de s'intéresser aux frontières séparant les nations, l'étude de la spatialisation des frontières peut se faire pas à pas, en allant des frontières de l'individu jusqu'à celles de groupes restreints. De ce processus de recherche allant du général au particulier, une approche théorique peut être dégagée. Si l'étude des frontières spatiales ou non, de l'individu au groupe, est pertinente, c'est parce qu'elle permet de déconstruire l'objet de recherche qu'est la frontière et de le traiter comme un concept abstrait dégagé de l'imbroglio social qui se cache dans le sens commun. Ainsi, mise à nu, la frontière nationale peut être étudiée comme faisant partie d'un processus de territorialisation d'une

${ }^{2}$ Eskualdun Ona 8.zenb. 1904. urtea

3 Il s'agit d'un résumé de ma thèse soutenue en décembre 1998 à l'Université de Pau et des Pays de I'Adour. 